\title{
Blue Jay Story Contest for Students
}

The number of boys and girls reading "The Blue Jay" increases with each issue. Following discussions at the Annual Meeting, a resolution was passed, sponsored by Mrs. John Hubbard, of Grenfell, that the boys and girls be encouraged to contribute their nature observations, and that prizes be awarded, each issue, for the best short story.

So boys and girls, let's have something from you right away. Here are the rules:

1. Any school student may enter. Age and grade will be taken into consideration by the judges.

2. Write a story telling about some original nature observation. Let it be a story of some bird or animal and its habits; of wild flowers which have been of special interest to you; how to build a bird house or feeding station; or any similar story about wildlife in your district. It must be something that you have seen or done yourself.

3. Don't make your stories too long; limit them to a maximum of 350 words.

4. Send your name, address, age, grade and school.

5. Mail your article to The Editor, The BLUE JAY, 1077 Garnet St., Regina.

6. A choice of Peterson's Field Guides (birds, mammals or butterflies) or Wherry's "Wild Flower Guide" plus a subscription to "The Blue Jay" will be given as prizes for the best story received for each issue.

7. The letter must be received by the Editor before February 1, or May 1, or August 1, or October 1. The winning story will be published in the issue following these dates.

8. When Saskatchewan celebrates its Jubilee Year in 1955, special prizes will be awarded for the best contributions received up to August 1 of that year.

\section{A GAME OF HIDE- AND-GO-SEEK \\ By FREDA M. CLAUS}

It all happened one June morning, when I heard the excited scolding of a chipmunk. I looked out of the kitchen window and saw a male bluebird chase the animal from one end of the leanto, opposite the stable, to the other.

The chipmunk, with a seemingly teasing succession of chirps, appeared momentarily at the west end of the leanto and, as soon as the bluebird fluttered dangerously near him, he would disappear under the rafters. In a moment, with another series of laughter-like chirps and an intermittent twitching of his tail, he would reappear at the east end.

The bluebird, more determined and more flustered each time the chipmunk suddenly reappeared, did not, for an instant, give up the chase. In fact, the game continued for some time before the chipmunk apparently decided he had had enough for that day, and did not appear again.

I still do not know the cause of this game of hide-and-go-seek, but, not far from the stable, in an old binder twine box, I, later, discovered four pale blue eggs, and although my enthusiasm was purely professional, I doubt if the chipmunk shared it.

\section{BOTANIZING IN CALIFORNIA} AUGUST J. BREITUNG

During the past summer, I made extensive botanical collections, totaling over 3,000 numbers ranging from the Mexican border northward through Nevada, Utah, Idaho, Montana and the Canadian Rockies. Since last Christmas, I have travelled about 17,000 miles by car. Of course, here in southern California, one can collect plants in flower all year round. Yesterday the temperature reached $80^{\circ} \mathrm{F}$; hummingbirds hover constantly over the large scarletflowered Hibiscus bushes outside the window; a flock of Brewer's blackbirds (with Saskatchewan accents) gorge on the dates fallen from the palm trees on the front lawnand I spend all my spare time studying this year's collections and dreaming of the glorious summer in mountains, deserts, along rivers and ocean sides. 